\title{
Knowledge sourcing and knowledge reuse in the virtual product prototyping: an exploratory study in a large automotive supplier of $\mathbf{R} \& D$
}

\author{
Raffaele Filieri ${ }^{1}$ and Salma Alguezaui ${ }^{2}$
}

(1) Newcastle Business School, Northumbria University, City Campus East, Newcastle Upon Tyne, NE1 8ST, UK

E-mail: raffaele.filieri@northumbria.ac.uk

(2) Department of Business Engineering, Università del Salento, via per Monteroni s.n. Lecce, Italy

\begin{abstract}
The capacity of organizations to share knowledge is seen as a source of competitive advantage in many industries. Knowledge sourcing and knowledge reuse have been indicated as important enablers of organizational efficiency and innovation performance. Although firms may own valuable knowledge, the presence of barriers to knowledge sourcing and reuse may hinder the exploitation of such knowledge. The present study explores the barriers to knowledge sourcing and reuse from electronic repository and their implications within the virtual product prototyping stage of new products development. The study is based on 24 interviews with research and development $(R \& D)$ employees of a large supplier of $R \& D$ in the automotive sector. Results demonstrate that the poor operational quality of a repository hinders knowledge sourcing; thereby, people prefer sourcing knowledge from other colleagues rather than from the repository. Moreover, the inefficiencies in knowledge sourcing from a repository, the poor quality of the codified knowledge and its complexity affect the reuse of existing knowledge. This study reveals that knowledge sourcing and knowledge reuse can affect the time performance in the virtual product prototype development process.
\end{abstract}

Keywords: knowledge reuse, knowledge sourcing, technical solutions, electronic knowledge repository, product prototyping process, automotive industry, new product development

\section{Introduction}

The achievement of competitive advantages urges organizations to manage knowledge, namely to acquire, integrate, store, share and apply increasing amount of knowledge (Prahalad \& Hamel, 1990; Grant, 1996, Davenport \& Prusak, 1998; Kankanhalli et al., 2005; Watson \& Hewett, 2006). Many firms recognize knowledge management as a key success factor of their business (Ofek \& Sarvary, 2001) and are increasingly improving their knowledge management activities in an attempt to make people access the right knowledge at the right time in the right format to increase organizational performance (O’dell \& Grayson, 1998; Gray \& Meister, 2006). Research has demonstrated that the reuse of knowledge is critical to a firm's performance because it affects its organizational effectiveness and can result in time saving (O’dell \& Grayson, 1998; Markus, 2001; Dixon, 2002; Haas \& Hansen, 2007).

The virtual product prototype development (VPPD) is a stage of the new product development (NPD) process where R\&D people from different areas of a company work together in a virtual environment to develop solutions for the problems that emerge during the design and assembly of a vehicle's parts. The VPPD is a knowledge-intensive process in which $\mathrm{R} \& \mathrm{D}$ people generate vast amounts of knowledge, such as pictorial, symbolic, linguistic, virtual and algorithmic knowledge (Owen and Horváth). Such knowledge is stored in knowledge repositories, manuals, technical reports and so forth (Corallo et al., 2009). Because most of NPD projects are not 'clean-sheet' efforts, rather incremental redesigns of existing products (Chandrasegaran et al., 2013), R\&D people often retrieve and reuse existing knowledge to solve recurring problems in the design of new products. The reuse of existing design knowledge is the key to realize rapid product design (Lu et al., 2011). However, no research has investigated the importance and the role of knowledge sourcing (KS) and knowledge reuse (KR) within the VPPD in the automotive sector. For instance, it is valuable and current to investigate the role of knowledge sourcing and reuse from a repository within the product prototyping process.

Although valuable knowledge (e.g. best practices, solutions) may be present within a firm (O'dell \& Grayson, 1998), the same knowledge can be difficult to locate and reuse in new projects because of the presence of barriers that hinder its sourcing and reuse. Therefore, a key challenge for organizations is to identify and overcome potential barriers that affect the retrieval and reuse of knowledge from a repository within their boundaries (O'dell \& Grayson, 1998). Researchers have started to investigate the type of 
'frictions' that slow or prevent knowledge sharing and are likely to erode some of its advantages; however, these studies are often focused on the contributor of knowledge (e.g. Constant et al., 1996; Hansen, 1999; Jarvenpaa \& Staples, 2000; Wasko \& Faraj, 2005; Durcikova \& Gray, 2009). Thus, there is limited research on the receivers of knowledge flows (Goodman \& Darr, 1998; Markus, 2001; Dixon, 2002; Kankanhalli et al., 2005) and qualitative studies of the factors that affect KS (Gray \& Durcikova, 2006; Gray \& Meister, 2006) and KR are needed (Markus, 2001; Dixon, 2002; Majchrzak et al., 2004; Kankanhalli et al., 2005) within the different stages of the NPD process.

In this study, we attempt to fill these gaps by exploring the range of potential barriers that affect KS and KR from the receiver's perspective, and the role that $\mathrm{KS}$ and $\mathrm{KR}$ play within the VPPD in the automotive industry, whose knowledge management activities are attracting the attention of scholars in recent years (Dyer \& Nobeoka, 2000; Kotabe et al., 2003; Lakshman \& Parente, 2008; Wolf et al., 2011). This study is based on 24 interviews with line managers and R\&D employees of a first-tier supplier of R\&D to a large automotive group.

The article begins with a summary of the relevant literature relating to KS, KR and VPPD. Then, it proceeds with a description of the research context and the research method. Afterwards, the results are displayed and discussed. Finally, the academic and managerial implications are reviewed, and conclusions and future research directions are drawn.

\section{Current literature}

\subsection{Knowledge sourcing, knowledge reuse and electronic knowledge repositories}

Knowledge management is the process of capturing, storing, sharing and using knowledge (Grant, 1996). Knowledge refers to a fluid mix of framed experiences, values, contextual information and expert insights, providing a framework for evaluating and incorporating new experiences and information (Davenport \& Prusak, 1998). The importance of knowledge and of how firms acquire and share knowledge is increasingly attracting the attention of scholars and practitioners (Kankanhalli et al., 2005; Kane \& Alavi, 2007). The effecti veness of intra-firm knowledge sharing has been identified as a critical factor of a company's success (Eisenhardt \& Santos, 2002) and as a driver of innovation (Kogut \& Zander, 1992; Dyer \& Nobeoka, 2000; Lilleoere \& Hansen, 2011). Knowledge sharing is defined as 'the provision or receipt of task information, know-how, and feedback regarding a product or procedure' (Hansen, 1999; Cummings, 2004, p. 352). The process of knowledge sharing includes three actors: the producer, the intermediary and the consumer (Markus, 2001). In this study, we focus on the consumer of knowledge (or knowledge seeker), which has received less attention compared with the producer of knowledge (Markus, 2001;
Dixon, 2002; Kankanhalli et al., 2005). Moreover, this study investigates the processes of retrieving and reusing pre-existing, codified knowledge within a repository, which are particular knowledge-sharing processes.

Drawing on Levitt and March (1988), Gray and Meister (2006) define KS as the 'extent to which individuals inte ntionally access other's expertise, experience, insights and opinions' (p. 144). In this study, KS is related to the activity of individuals searching for and accessing the knowledge that has been codified and archived by people within the same organization into an electronic repository. Research on KS is still scant (Kankanhalli et al., 2005). Gray and Meister (2006) investigated different sourcing methods (i.e. knowledge repositories and virtual communities of practice) and their impact on different performance outcomes (replication, adaptation and innovation). Scholars have also analysed the motivation of technical support analysts for accessing to knowledge from repositories, as opposed to other sources such as colleagues and manuals (Gray \& Durcikova, 2006), and the motivation of public sector employees for using electronic knowledge repositories to seek for knowledge (Kankanhalli et al., 2005).

Knowledge reuse refers to the activity of an individual (or a group) within an organization using knowledge generated by a different individual (or group) within the same organization in order to be more effective and productive in their work (Alavi \& Leidner, 2001). There is a paucity of research on KR. The work of Markus (2001) sheds light on the specific conditions under which successful KR is likely to occur, suggesting that the higher the match between the needs of re-users and the resource provided in the repository, the more KR will occur. Ettlie and Kubarek (2008) analysed the impact of design reuse decisions on the novelty of product and service offerings, while Cheung et al. (2008) showed that the reuse of knowledge from an intranet-based knowledge repository inhibits the creative performance of individuals. Durcikova et al. (2011) investigate the influence of climate for innovation and knowledge management systems access on solution reuse and solution innovation.

From this review of the KS and KR literatures, it emerges that scholars have not undertaken an in-depth investigation of the factors that affect $\mathrm{KS}$ and $\mathrm{KR}$, how these processes relate to each other and their implications within a specific stage of the NPD. Majchrzak et al. (2004) distinguished between KR for innovation (also termed exploration) and KR for exploitation (March, 1991), where KR for exploration refers to the development of new knowledge within the organization's memory (Abernathy, 1978; March, 1991), whereas KR for exploitation refers to incremental learning focused on diffusion, refinement and reuse of existing knowledge (March, 1991; Larsson et al., 1998). Similarly, Durcikova et al. (2011) view solution innovation as a form of knowledge exploration and solution reuse as a form of knowledge exploitation. While some research has been conducted on KR for exploration (Majchrzak et al., 2004; Watson \& Hewett, 2006; Cheung 
et al., 2008; Ettlie \& Kubarek, 2008; Durcikova et al., 2011), little attention has been dedicated to knowledge exploitation (Gray \& Meister, 2006; Durcikova et al., 2011). Design KR is key in the VPPD, and the more R\&D employees can reuse existing components, the lower the design loads and the more rapid the product development (Lu et al., 2011). In this study, we focus on KR for exploitation in the VPPD, namely on the replication of existing knowledge into new projects with the aim of improving organizational performance.

Researchers distinguish between two main strategies to knowledge sharing: a codification and a personalization strategy (Hansen et al., 1999). The personalization strategy is based on person-to-person learning, in which knowledge is shared with other people (employees) through face-to-face communications, including on-the-job learning, storytelling, training activities and communities of practice (Brown \& Duguid, 2001). The codification strategy is instead based on the document-to-person approach, in which people retrieve codified knowledge from knowledge management systems, databases, books, data warehouses, decision support systems and enterprise resource planning systems (Hansen et al., 1999). Two types of knowledge management systems have been developed for supporting these two strategies: know ledge directories (e.g. yellow pages) and knowledge networks (e.g. electronic communities of practice) support the persona lization strategy, while electronic knowledge repositories support the codification strategy as they store codified knowledge for future adoption (Hansen et al., 1999; Markus, 2001; Kankanhalli et al., 2005). Electronic knowledge repositories are documents or repositories that facilitate knowledge and information search, organization, storage and retrieval (Wu \& Wang, 2006). Repositories are used by companies to enable employees dispersed in different locations to access the company's best practices, lessons learned and know how. The current study focuses on the sourcing and reuse of technical solutions to vehicle design anomalies (e.g. interferences) that have been archived by $\mathrm{R} \& \mathrm{D}$ employees of the same organization in the company's knowledge repository.

\subsection{Virtual product prototyping in the automotive industry}

In the knowledge economy, the competitive advantage of firms stems from their capacity to favour organizational learning for fostering innovation (Nonaka, 1991; Grant, 1996; Watson \& Hewett, 2006). The innovation process is regarded as a create knowledge, transfer knowledge and exploit knowledge cycle, including the activities of searching for and spreading organizational knowledge (Argote et al., 2003; Carlile \& Rebentisch, 2003).

Cooper (1990) developed a model that divides the innovation process into a seven-stage process, each stage being composed of a group of activities, roles and responsibilities. The virtual product prototyping is the stage that precedes a company's approval of a product concept and anticipates the virtual and physical test of a new product (Cooper, 2008).
The rapid development of manufacturing and information technology has enabled firms to manufacture increasingly sophisticated industrial products, and the importance of the technology for product assemblies has been increasing (Xu et al., 2012). In the automotive sector, many car manufacturers have recently introduced virtual simulation methods to improve the performance of this process. Virtual simulation software tools (i.e. AutoAssem or the digital mock-up, DMU), namely software tools for planning and scheduling of manufacturing activities at workcells or at system level (Xu et al., 2012, p. 669), are significantly changing the way firms design new products and analyse and resolve technical problems (Dodgson et al., 2007). The simulation-based development method can be completed before a physical prototype is built, which can reduce the time and the cost of the vehicle development process (Butterfield et al., 2007; Sun et al., 2011) as well as it can improve the efficiency of assembly planning and reduce the possibilities of failures (Xu et al., 2012).

A virtual prototype of a vehicle is obtained through the integration of single computer-aided engineering (CAE) and mathematics of the different vehicle components into a single numeric model. The integration of the different designs is achieved through the DMU that is a technology enabling the virtual display of a vehicle in three dimensions, allowing the visualization of the whole product. The core assembly planning capabilities of the DMU software include the following: (1) interfaces of manual settings for assembly sequence, (2) assembly simulation and exporting, (3) interference detection and (4) dynamic visualization (Xu et al., 2012).

In the context of vehicle assembly, the DMU is aimed at integrating the sub-components of a vehicle by defining its configuration, position, connections, potential interference between the components and functional specifications related to the interface, reliability, security, aesthetics, ergonomics and assembly. If from one side the use of simultaneous and collaborative design processes can provide several benefits to organization, on the other side, the effectiveness of the process depends on how effective the knowledge is transferred between teams (Chandrasegaran et al., 2013). Scholars have emphasized that there is a lack of detailed information of how digital assembly technologies are implemented (Butterfield et al., 2007). The current study investigates the implications of $\mathrm{KR}$ and $\mathrm{KS}$ from an electronic repository during the design of a virtual vehicle prototype through the DMU.

Although there is an increasing amount of research on knowledge sharing in the automotive sector (Dyer \& Nobeoka, 2000; Kotabe et al., 2003; Lakshman \& Parente, 2008; Wolf et al., 2011), research on the knowledge-based activities in the virtual product prototyping is currently at an embryonic stage (Vaccaro et al., 2011). Although research has explored the relationship between knowledge management and innovation performance (e.g. Yli-Renko et al., 2001; Yu et al., 2014), to the best of our knowledge, no research has yet explored the implications of KS and 
KR from an electronic repository in the product prototyping stage of NPD. With the present study, we attempt to provide an indication of how knowledge sourcing and reuse from an electronic repository affect the performance of the vehicle prototyping process.

\section{Methodology}

\subsection{Method and context of the study}

A qualitative method of investigation has been adopted in this study because of the novelty of the phenomenon under investigation (KS and KR within the VPPD) (Yin, 2003) and because of the number and complexity of potential barriers to consider in research on $\mathrm{KS}$ and $\mathrm{KR}$, such as the characteristics of the repositories, the characteristics of indi viduals adopting such technologies and the organizational environment in which they are adopted (Kane \& Alavi, 2007).

Following the approach adopted by previous scholars (Gray \& Meister, 2006; Watson \& Hewett, 2006), we have conducted research on KR and $\mathrm{KS}$ in a single company. This study is based on the automotive industry, which is a typical example of knowledge-intensive industry (Jordan \& Jones, 1997). The decision to study only one R\&D centre was forced by the fact that the automotive industry is a very competitive industry and automotive companies have very strict guidelines to protect their intellectual capital. Automotive companies have several limitations regarding external people doing research within their R\&D centres because knowledge is a key asset to their competitive advantage and the perceived risk of losing such advantage due to inadvertently disclosing critical knowledge is high.

The automotive industry requires huge investments in the creation of technological knowledge and in the sharing of knowledge for the development of new products. The decision to select the current automotive group was taken because this company is one of the largest automotive groups in the world and has been very successful in overcoming the economic recession through the launch of several new products in a very short time.

\subsection{Interviews}

Interviews with repository users have been undertaken to get an in-depth understanding of the phenomenon under investigation and to inductively develop an empirically grounded theory (Glaser \& Strauss, 1967). The seven-step procedure proposed by Kvale (2007) for conducting interviews was followed, which includes thematization, design, conduct the interview, transcription of interviews, analysis, validation and reporting.

Thematizing an interview study involves explaining the purpose of the study, namely the why and what of a study (Kvale, 2007). Interviews can be adopted to inductively develop an empirically grounded theory (Glaser \& Strauss, 1967; Kvale, 2007). The purpose of this study is to develop a new theoretical model that would include the antecedents to KR and KS, and the implications of KR and $\mathrm{KS}$ for the VPPD.

The literatures on KR and KS and on product prototyping have been reviewed in order to acquire a base to which new knowledge will be added and integrated (Kvale, 2007). In addition, to obtain a pre-knowledge of the subject matter to be investigated, the researcher collected proprietary documents and other information on the company's vehicle prototyping process (Kvale, 2007). Afterwards, the researcher arranged interviews with $\mathrm{R} \& \mathrm{D}$ employees, which had different roles and responsibilities, from three business units within the organization, namely vehicle, motor propulsion (MP), and information and communication technology (ICT). However, the research started within the ICT business unit, after the other two business units were involved through the mediation of the director of the ICT business unit. The purposive sample method informed the selection of the business units, which were chosen to participate to this study for their relevancy in the prototyping of the most recent vehicle models. The vehicle business unit directly creates and manages the knowledge needed for the development of a vehicle, whereas the MP business unit generates and manages the knowledge in the area of motor propulsion and engines, while the ICT business unit defines and develops the methodologies and the applications for knowledge archival, retrieval and reuse. To elicit honest answers from the sample, the researchers have assured that the study was carried out with the aim of improving business processes and that the answers would not have been shared with other employees.

Twenty-four R\&D people took part to face-to-face interviews; the length of interviews varied from 45 to $55 \mathrm{~min}$; a typical interview was about $50 \mathrm{~min}$ (interview stage). To ensure consistency and speed up the analysis, all of the interviews were carried out by the same researcher and transcribed at the end of each interview without waiting until all interviews were completed (Silverman, 2010). A total number of 24 interviews was judged as sufficient for reaching a theoretical saturation (Strauss \& Corbin, 1998), as additional interviews were adding little or no new knowledge to what was already discussed in the first 18 interviews (Kvale, 2007). Table 1 shows the profile of the interviewees in relation to age, gender, education level, work experience in the company and role.

The format of semi-structured interview was chosen. Interviewees were first informed about the purpose of the study, the data treatment and storage, and the ethical issues. Then, they were given the definitions of knowledge, $\mathrm{KS}$ and KR. Because of knowledge being an ambiguous object of investigation, it is paramount to specify the type of knowledge that is the object of investigation in this study. At the VPPD, R\&D people are more likely to transfer knowledge that is related to what they already know and are more likely to pursue exploitative innovations as well (Jansen et al., 2006). The knowledge required in the VPPD stage of NPD is mainly productspecific technical know-how (Hansen, 2002), which is the 
Table 1: Socio-demographic characteristics of the interviewed $R \& D$ employees

\begin{tabular}{|c|c|c|c|c|c|}
\hline ID & Gender & Age & Education & Work experience & Position \\
\hline 1 & M & $26-35$ & Postgraduate & $5-10$ & Designer \\
\hline 2 & M & $26-35$ & Undergraduate & $5-10$ & Designer \\
\hline 3 & M & $36-45$ & Postgraduate & $10-15$ & PM \\
\hline 4 & M & $46-54$ & High school & $>15$ & PM \\
\hline 5 & M & $26-35$ & Postgraduate & $5-10$ & Designer \\
\hline 6 & M & $36-45$ & High school & $>15$ & PM \\
\hline 7 & M & $36-45$ & Postgraduate & $>15$ & Designer \\
\hline 8 & $\mathrm{M}$ & $26-35$ & Undergraduate & $5-10$ & Designer \\
\hline 9 & M & $36-45$ & Postgraduate & $10-15$ & PM \\
\hline 10 & M & $36-45$ & Postgraduate & $>15$ & Head of Dep \\
\hline 11 & M & $26-35$ & Undergraduate & $5-10$ & PM \\
\hline 12 & M & $36-45$ & Postgraduate & $>15$ & SA \\
\hline 13 & M & $26-35$ & Postgraduate & $5-10$ & SA \\
\hline 14 & $\mathrm{~F}$ & $36-45$ & Postgraduate & $>15$ & Designer \\
\hline 15 & M & $36-45$ & Undergraduate & $>15$ & SA \\
\hline 16 & M & $36-45$ & Undergraduate & $5-10$ & PM \\
\hline 17 & M & $26-35$ & Postgraduate & $<5$ & CAE analyst \\
\hline 18 & M & $46-54$ & High school & $>15$ & Head of Dep \\
\hline 19 & M & $36-45$ & Postgraduate & $>15$ & Designer \\
\hline 20 & M & $36-45$ & Postgraduate & $>15$ & Designer \\
\hline 21 & M & $26-35$ & Postgraduate & $5-10$ & CAE analyst \\
\hline 22 & M & $36-45$ & High school & $10-15$ & PM \\
\hline 23 & M & $36-45$ & Postgraduate & $5-10$ & $\mathrm{SA}$ \\
\hline 24 & M & $36-45$ & High school & $>15$ & TL \\
\hline
\end{tabular}

SA, systems analyst; TL, team leader; PM, project manager; CAE analysts, computer-aided engineering analyst.

type of knowledge being created and reused for solving problems. Therefore, interviewees were told that the term knowledge referred to codified solutions archived into the electronic repository by other $\mathrm{R} \& \mathrm{D}$ employees. Interv iewees were then asked to comment about their typical work day and to provide information about their work processes. Subsequently, they were asked to discuss more in depth about KR and KS. Our interview protocol followed the critical-incident technique (Flanagan, 1954); namely, interviewees were asked to recall the last time they retrieved and reused knowledge from the organizational electronic repository. Subsequent questions investigated the presence of potential obstacles that obstructed the respondent's sourcing and reuse of knowledge from the repository during the product prototyping process, which pertains to theoretically informed interview questioning (Kvale, 2007). Moreover, interviewees were also asked to comment how the KS and KR relate to VPPD and the type of impact these processes produced on it. Interviewees were also asked to propose viable solutions to the problems arising from the interviews. During interviews, documents about the company's VPPD, previously shared by the head of department with the researcher, were also analysed and commented on.

The transcription stage concerns information on how the interviews were recorded and transcribed (Kvale, 2007). All interviews were tape-recorded and transcribed verbatim by the researcher.

The data analysis of interviews adopted the open and axial coding methods proposed by Strauss and Corbin (1998). Open coding was used to shed light on the properties and dimensions of concepts in the dataset. Axial coding was used for crosscutting and relating concepts/categories to each other and for identifying the how or the means through which a category is manifested (Strauss \& Corbin, 1998). To recognize themes and uncover relationships, we followed the Strauss and Corbin (1998) recommendation to distinguish between conditions, actions/interactions and consequences. The themes referring to the barriers to $\mathrm{KS}$ and $\mathrm{KR}$ mentioned in interviews were derived from theory (Kvale, 2007) and were respectively repository ease of use and knowledge quality. Then, we were able to identify sub-categories or themes discussed by interviewees, which referred to the two categories. The data from interviews were useful to understand the specific relationships between $\mathrm{KS}$ and KR, and whether and how KS and KR impacted on the VPPD. The coding scheme developed by one of the researcher was shared with two doctoral students who were not involved in the research project to perform independent coding. The coders were first trained on how to code qualitative data from interviews, and then, they were given the entire dataset and asked to code it in two separate locations. There was some disagreement between the coders mainly because of ambiguities in the definitions and labels provided in the schema. However, no new categories were found, and after the modifications of some sub-categories, labels and definitions, the disagreement was solved.

In order to further check the validity and the reliability of the analysis, the researcher discussed the results with key informants within the company through informal discussions and a presentation. 


\section{Results}

\subsection{Repository ease of use and knowledge sourcing}

From interviews, we have acknowledged that the ease of use of the knowledge repository is an important barrier to KS. Ease of use is referred to as the degree to which a person believes that using a technology would be free of effort (Davis, 1989). Ease of use is conceptualized as the perceived time and effort needed to retrieve knowledge from a repository (Goodman \& Darr, 1998). The KS activity entails the formulation of a query and the refining of the search, until some satisfactory output is obtained or the knowledge seeker gives up with the search (Kankanhalli et al., 2005).

Interviewees have the perception that the difficulty of use of the repository has a negative impact on KS. Employees in this R\&D supplier adopt an in-house developed repository (named 'KMAN') where they archive knowledge (i.e. solutions) that is reused during the vehicle prototyping process. However, during interviews, R\&D staff mentioned that the sourcing of solutions from the repository was difficult and time consuming. The repository was perceived as difficult to use for different reasons including the following: ambig uous repository and folder labels, lack of interoperability between different repositories and systems, and ineffective search functionalities. Respondents stated that knowledge repositories and folder labels have been created by employees without following specific organizational rules or norms. According to interviewees, the lack of archival norms was due to a lack of preliminary cross-unit discussions on the most appropriate label or term to be used to archive a specific type of knowledge into the repository. Respondents said that they often have to deal with folders and repository with very generic labels/names, and such ambiguity has led to a duplication of repositories, folders and documents. Such a duplication of labels has generated some confusion among R\&D staff, making it difficult for them to source the right knowledge for solving problems.

'....problems [when sourcing knowledge] occur when I need some document for fixing vehicle development anomalies (from the repository). It is very difficult to retrieve the right documents rapidly.... This is frustrating since I have to search for the right document in every folder and then I have also to browse the documents to see if the solution I have found is the correct solution to the current problem. The main problems of KMAN are the search functionalities and the folders... search functionalities are not effective in helping to find what one is looking for and folders have ambiguous labels...my colleagues often create new folders because they do not understand - or do not know - what has been archived in other folders and repositories by other people....I think they codify the solutions for themselves, not thinking that other people will search for these solutions in the future' [Team Leader, MP]
Interviewed R\&D employees propose the adoption of ontologies as a solution to the KS problem. They suggest that the key-word-based search functionalities actually in use are not effective in retrieving the solutions that they need to solve problems. Accordingly,

'...I think the main problem of our repository is due to the key-word search system. This kind of research involves only the syntactic/lexical aspects, and not the semantic ones. In my opinion the adoption of ontologies for the vehicle might help...' [System Analyst, ICT]

'...problems come from the applications used to archive knowledge....in my opinion retrieving the solution that is needed to solve an irregularity takes too much time... search functionalities are not helpful at all...the problem could be solved through the adoption of ontologies for indexing the documents... Ontologies may facilitate the retrieval of documents containing the same typologies of irregularities and their solutions. In relation to this, we have an ongoing research project with the University of ...which is aimed at identifying and defining domain ontologies...' [System Analyst, ICT]

Some of the interviewees also emphasize the lack of interoperability between the different systems in use as one of the main problems, which affects the ease of use of the repository and in turn has a negative impact on KS. This problem is particularly evident in the anomaly solution process, where people from different business units and suppliers work together to build a vehicle prototype in a virtual environment:

'The main difficulty in the sourcing of knowledge derive from the fact that different business units use and consequently archive knowledge into different applications. These systems do not communicate between each other...for this reason the solution I'm looking for may be archived into a system that we are not using actually...employees should all use the same applications and the same archival method (throughout the company). However, it is also true that different business units do different things and adopt different applications to do these things ... for example designers (at Vehicle) adopt Iman and Codep...' [CAE analyst, Vehicle]

\subsection{Knowledge quality and knowledge reuse}

The data from interviews reveal that the quality of knowledge is a main issue in the process of $\mathrm{KR}$ and knowledge quality is a critical barrier to KR. In this context, R\&D people refer to knowledge quality as the accuracy, completeness and format of codified knowledge. Respo 
ndents complain about the lack of accuracy and completeness of the codified knowledge, and about the inconsistent adoption of a standard format of representation of the codified knowledge.

It emerges that the codification of knowledge is a routinized activity within this R\&D supplier; namely, $R \& D$ employees who are involved in the anomaly solution process have to codify any new solution being generated, and they have to subsequently archive it in the knowledge repository. As a matter of fact, the repository contains a large amount of codified solutions to anomalies occurring in the vehicle prototype development process. Many types of anomalies emerge frequently during the VPPD, and the purpose of knowledge codification is to enhance its reuse so as to accelerate the problem-solving process. However, both the lack of accuracy of the codified solutions and the failure of $\mathrm{R} \& \mathrm{D}$ employees to adopt a consistent format of representation (for the codification of solutions) hinder the possibility of reusing the same solution for fixing recurring anomalies. Knowledge accuracy is defined as the correctness in the mapping of stored information to the appropriate state in the real world that the information represents (Nelson et al., 2005). Knowledge is judged as accurate if it is correct, meaningful, easy to understand and not ambiguous (Nelson et al., 2005).

'...during these years, we have created loads of data and documents about vehicle design, implementation and development and archived them into our repository ...however, the knowledge contained in such documents is quite unusable because other employees from other business units and external suppliers have never systematically used the same templates, libraries, taxonomies, keywords or a shared terminology...I think that most of my colleagues do not think that these solutions can be searched and used by other people' [System Analyst, ICT]

The capacity to make knowledge reusable to other people in the organization depends on the adoption of shared templates/formats, which can improve its representational consistency. Knowledge format refers to the degree to which knowledge is presented in a manner that is understandable and interpretable to the user and thus aids in the completion of a task (Nelson et al., 2005). Organizations use specific forms and templates to codify and archive knowledge in order to facilitate its understanding and reuse. The adoption of a format for knowledge codification implies that knowledge has to be codified in a way that is immediately meaningful to every employee in order to be reusable. In this $\mathrm{R} \& \mathrm{D}$ supplier, people complain about the lack of adoption of a consistent format of representation of knowledge. Among the solutions proposed, there is the adoption of more clear terms and language, the provision of correct information and measurements, and the adoption of a shared format, terminology, templates and taxonomies.
'...When we have started to create, formalize (and archive) the solutions to anomalies into a document, we did not define a common set of rules for this activity...this was a big mistake... Thus, everybody does formalize solutions his own way ...using his own vocabulary and style and this make it difficult for other users to understand and to apply past solutions to new projects....' [System Analyst, ICT]

Together with the lack of adoption of a consistent format of representation, the degree of completeness of the information provided in the existing documents also affects the reuse of knowledge from a repository. Completeness refers to the degree to which all knowledge needs are covered by the knowledge stored into the repository. Respondents state that codified knowledge is sometimes not exhaustive and complete for solving the emerging assembly problems; thus, they complain about the lack of completeness of the information provided into the archived documents. Codified knowledge is not perceived to completely satisfy their information needs as documents do not always provide all of the relevant information needed to solve an irregularity, such as the type of anomaly, its diagnosis, the corrective action to be taken, the assembly unit and the parts involved, connections, mathematics and so on. This problem requires $R \& D$ people to contact the author of the document in order to get clarification. Therefore, even though vast amounts of knowledge have been archived into the repository, $\mathrm{R} \& \mathrm{D}$ people still need people-to-people interactions to understand and apply knowledge. This means that the time savings benefits related to searching for a solution in an electronic repository wear off when a document does not contain all the knowledge that $R \& D$ people are expecting to find in it.

'When I retrieve past documents for solving current anomalies I frequently find that the irregularity schedule [excel template used for the irregularity audit] is not used consistently. Moreover, someone does not use this template; sometimes some information in the template are missing or placed in the wrong place, which requires additional phone calls to fill all the areas of the template and finally being able to adopt the solution... To be honest, I'm not sure if I save time by doing this...a quicker way is to contact the RVP [responsible for project audit] for a specific anomaly' [Designer, Vehicle]

\subsection{Knowledge complexity}

The complexity of the knowledge needed to solve problems during the VPPD is also viewed as an important barrier to KR. Knowledge complexity, especially in product develop ment tasks, 'is the extent to which the knowledge to be transferred is independent or is an element of a set of interdependent components' (Teece, 1986; Winter, 1987; Hansen, 1999, p. 87). In this contest, the knowledge that 
has to be reused is dependent on other pieces of knowledge; namely, the vehicle module works in conjunction with other components. Reusing a piece of knowledge will require that the person receiving it has some knowledge of the system as a whole, of which the piece of knowledge is only a part. The codified knowledge may also need to be modified to work in the new project. Accordingly, R\&D people have discu ssions regarding the complexity of knowledge, which is caused by the high number of parts a vehicle is made of and the interdependency among these parts. In fact, modern mechanical products such as vehicle body parts are made of hundreds or thousands of parts because of the complexity of functionalities (Lee \& Saitou, 2004; Xu et al., 2014). Each part of a vehicle body is a bunch of knowledge that interacts with other knowledge (parts) when R\&D people assemble the different components. A correct application of know ledge means that people understand in advance how the new knowledge (solution) will affect the other parts, components and sub-systems, and the vehicle design as a whole. In fact, R\&D people declare that, when they apply a solution related to a vehicle part (knowledge of the parts, sub-parts and their interrelations), they need to know how this addition/modification to the module will affect other parts and the whole system (knowledge of the system as a whole). Thus, this complexity of the knowledge required at this stage is a major impediment to KR from a repository:

'the vehicle prototyping is the result of the integration of multiple parts and sub-components, the application or modification of one part may affect other parts, sub-components and so on...the solutions we gather through the system can help us to solve problems but it is always difficult to understand how the solution that we apply interact with the other parts of the vehicle...you know each part interacts with other parts, the modification of one anomaly may lead to a new anomaly because the components are interdependent...it is complex .... at the moment we still need a lot of conversations between us to manage such complexity'

\subsection{Knowledge sourcing and knowledge reuse}

The analysis of interview data also enabled us to identify a relationship between KS and KR. Interviewees have stated that many $\mathrm{R} \& \mathrm{D}$ people are not using the electronic repository because it is difficult to locate the right knowledge for their problem solving needs. Therefore, the inefficiency related to KS from the repository has created a negative perception of the repository among employees: sourcing knowledge from the repository is seen as more time consuming than sourcing knowledge from other people. R\&D people also believe that the process of recreating a solution from a search is more efficient, rapid and easy than searching for a solution archived into the repository by other R\&D people.
'If I want to retrieve previous simulations to measure electromagnetic areas for checking interferences I will not go to search for a solution into Kman... I'd rather call my colleague and ask them for help...instead of spending a lot of time retrieving the knowledge archived by others somewhere into the system... retrieving the right solution from the system is often difficult and time consuming...' [Project Manager, Vehicle]

\subsection{Knowledge sourcing and reuse and product prototype development performance}

Findings from interviews reveal that effective KS and KR may reduce the performance of the virtual product prototyping process, and in particular of the time needed to develop a vehicle prototype. For instance, interviewees have emphasized the importance of efficient sourcing and the reuse of solutions from a repository. However, if from one hand efficient sourcing and reuse of knowledge can produce benefits, it is interesting to see that inefficiencies in KS and KR from a repository have a negative influence on NPD performance. To this regard, interviewees have discussions about the impact that KR and KS have on the issue management process, which is - according to the organization's terminology - the process through which R\&D employees from different departments and units identify and solve anomalies on different parts, systems and modules during the virtual development of a vehicle prototype.

'...reusing knowledge is problematic in the issue management process ...people are willing to share knowledge because you know this is fundamental in our work... When we start an ODM (Problem solving phase in which the irregularities found are solved by activating the cycle of Orders of Modification), the retrieval of the right knowledge is fundamental, because the same irregularity can emerge again and again in that same and other projects... The Digital Mock Up (DMU) detects the irregularity but it does not tell you how to solve it. This is our task... For instance, to rapidly solve an irregularity [which has been found in the past] we might adopt similar solutions by retrieving them into KMAN... Nevertheless, this is often difficult because my colleagues archive knowledge into different systems, they use different repository names, or they codify the solution in a way that is not clear to others...If you read some of these documents you may feel that they were very tired when they codified it... engineers do not like to write documents...thus, some documents lack accuracy, a systematic use of templates, and they are characterized by a subjective terminology.' [Head of Department, Vehicle] 
Thus, it seems that the low quality of the codified knowledge leads to scale diseconomies in the reuse of knowledge. Being knowledge difficult to reuse, R\&D people often have to recreate solutions from scratch and codify them, which leads to duplication of knowledge. Moreover, they also need to contact their colleagues to be able to source the right knowledge or to understand the codified knowledge or to solve a problem. As a result, to solve a problem by retrieving and reusing a solution from the repository, it takes more time and requires more effort than it is necessary. These problems make the processes of KR and KS from a repository inefficient, and show how people-to-people interaction is perceived as the most effective vehicle through which highly complex and ambiguous knowledge can be transferred. Furthermore, interviewees report that the retrieval of knowledge might be easier for the people who remember exactly where knowledge has been archived and what type of knowledge has been archived into the system. This means that electronic repository does not fulfil one of the promises that they should deliver, that is, to facilitate the retrieval of knowledge by those individuals with limited memory (Kane \& Alavi, 2007).

'...If I want to retrieve previous simulations for solving current interferences it is more rapid to solve the error by myself instead of retrieving past solutions archived by others into the system...some years ago the DMU was introduced.... The DMU is very effective and we have progressed a lot in terms of time and quality... the DMU enables us to identify the errors and the irregularities emerging in the vehicle prototype building... however, the DMU does not tell us how to solve the problems. For this reason, we retrieve the documents archived into KMAN for solving current anomalies...some employees have good memory and remember where they have archived previous solutions but most employees waste a lot of time searching for them...I often [re]create the solution to an irregularity by myself because the repository is messy and the retrieval of solutions is too slow... [Head of Department, Vehicle]

According to interviewees, the inefficiencies in $\mathrm{KS}$ and KR slow down the anomaly solution process, and they also have an impact on the work of other suppliers who work on the same platform project. Being the VPPD, an interdependent task in which different business units and different suppliers work together simultaneously in a virtual environment to build a virtual vehicle prototype, all the parties involved have to wait until a solution to the problem is found. Thus, the planning and scheduling of prototyping processes are affected by such delays.

"...the "Target Setting" or "Management of product requirements" is the process through which we transform the company's needs into technique goals for the building of a vehicle. In this process a fundamental task is the management of the irregularities/errors occurring during the development process of a new vehicle... the problems related to the retrieval and reuse of knowledge are particularly important if you consider that my colleagues have to recreate the same solutions to anomalies from scratch every time ...most of time such solutions have been already developed, codified and archived by other people... so if it takes a lot of time for solving an anomaly so you can understand the degree of the impact that this inefficiencies have on the time performance of the whole group... because we and ... [name hidden, R\&D centers and suppliers of the automotive group] work together on the same platform. So if we do not solve an anomaly quickly, the other supplier is blocked and cannot progress.... It is very difficult to quantify the impact on the prototype development process; I think that this problem may have an impact equal to $20 \%$ on the development time'. [Designer, Vehicle]

As mentioned earlier, some interviewees have attempted to quantify the impact that KS and KR have on the performance of the VPPD. However, respondents struggle to quantify such impact because of the recent introduction of digital simulation technologies in the VPPD, which according to the respondents have considerably accelerated the vehicle prototype development process. Thus, it would be misleading to try to compare current with the past performance in terms of the time needed to develop a vehicle prototype. However, the impact of KS and KR on the time performance of the VPPD is important as mentioned by interviewees:

'In the actual model we must manage a project in which people from different business units, with different roles (e.g., engineers, designers, mechanics) and different (parent) R\&D centers and companies work together on the same platform...thus, if we had efficiency in the logistics of knowledge and information across this supply chain, we could certainly reduce product lead times.' [Project Manager, MP]

From the results obtained, we have developed a theoretical model that is represented in Figure 1.

\section{Discussion}

The current study has explored the barriers to KS and KR from a repository and their implications for the performance of the virtual vehicle prototyping process. The research has been carried out within a first-tier supplier of $R \& D$ of a leading multinational company in the automotive sector.

The results of this study have led to development of a new theoretical framework that is illustrated in Figure 1. The framework highlights that the ease of use of a repository 


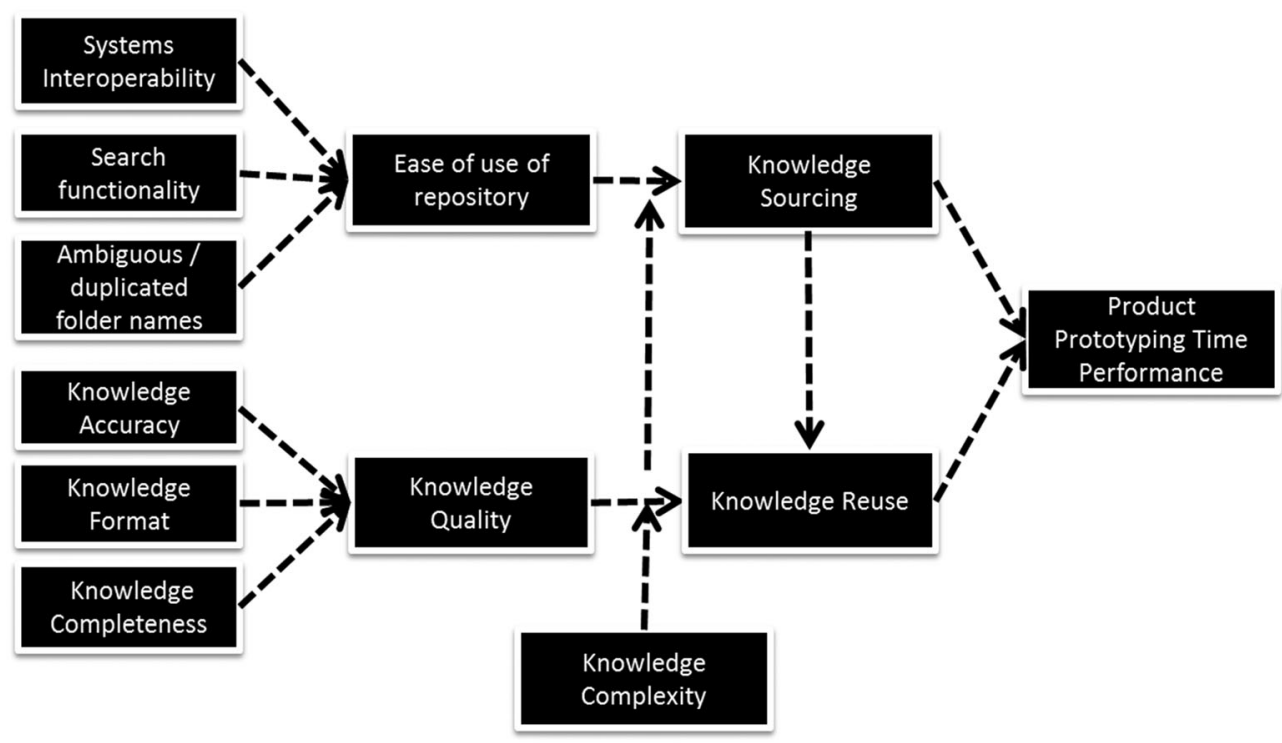

Figure 1: The theoretical model emerging from the data analysis.

from one side and knowledge quality from the other side have implications for the processes of KS and KR. The emerging framework also shows the moderating role of knowledge complexity, the influence of KS on KR, and that both KS and KR can have an influence on the time performance of the virtual product prototyping process.

The adoption of a digital manufacturing approach for assembly planning of complex products makes it possible to generate, analyse and evaluate feasible assembly designs in a short time (Xu et al., 2012, p. 676). In order to support these processes, organizations have implemented knowledge management systems in order to enable the sharing of the intellectual capital created by knowledge workers in the organization, thus increasing decision-making effectiveness and ultimately competitive positioning (Rao \& Osei-Bryson, 2007). However, as noted in the findings of this and previous research on knowledge management technologies, the simple adoption of a knowledge repository does not necessarily lead to successful knowledge management (Malhotra, 2004, Kankanhalli et al., 2005; Durcikova et al., 2011). In particular, we have found that an electronic knowledge repository does not enhance KS and KR because of the existence of the barriers documented in this study, namely poor knowledge quality and operational problems with the electronic repository.

Findings highlight that ease of use of a repository is an important factor to consider when a company wants to enhance KS. This result differs from the findings of Kankanhalli et al. (2005), as they revealed that the ease of use of a repository is not a significant factor to consider when investigating the motivation to use a repository for knowledge seeking in public sector organizations. Instead, we agree with Gray and Durcikova (2006), who found that the ease of use of a repository is an important antecedent of KS from a repository. In this study, it was found that $R \& D$ employees reduce the use of a repository when the retrieval and reuse of knowledge from a repository is perceived to be time consuming (Gray \& Durcikova, 2006). Our investigation into the perceived time-consuming nature of sourcing knowledge from a repository found that the lack of interoperability between different systems and repositories, the ineffective search functionalities (based on syntactic search only) and the ambiguous labels of the (often duplicated) folders/directories of repositories are important aspects to consider. Moreover, we have documented that, because of complexity of knowledge, people-to-people interactions seem to be the favoured method of sourcing knowledge, which emphasizes the importance of collaborative activities in the process of assembly (Wang et al., 2009).

Our findings also show the potential presence of a relationship between $\mathrm{KS}$ and $\mathrm{KR}$, which is also new to the literature. Previous studies found that the sourcing of published knowledge was a significant predictor of knowledge replication in a manufacturing engineering division (Gray \& Meister, 2006). In this study, we have found that, when R\&D employees perceive that the retrieval of a solution from a repository is difficult and time consuming, they will prefer to turn to their colleagues and/or to recreate the same solution once again instead of reusing an existing one.

Interestingly, the degree of ease of use of the repository affects the willingness of employees for seeking knowledge within a repository, and a negative perception of the ease of use and usefulness of a repository affect future reuse intentions. We have found that R\&D employees often decide not to retrieve solutions from a repository; instead, they prefer to source the needed knowledge from other colleagues within their organization. Thus, contrary to what is often stated, the access to and use of a knowledge management system do not necessarily enhance solution reuse in an organization. Rather, R\&D staffs still favour people-topeople interactions to solve complex problems. This seems 
to be dependent on the degree of complexity of the knowledge that is needed to build a vehicle. As mentioned earlier, knowledge complexity seems to act as a moderating factor in the relationship between system quality and KS and between knowledge quality and KR. This means that, in conditions of high knowledge complexity, organizations cannot completely rely on a people-to-document approach as some degree of interaction will be always needed. With the present finding, we also advance the literature on the benefits of knowledge codification within the product prototyping process. Codification has been considered an important vehicle for transferring knowledge (Ruggles, 1997; Davenport \& Prusak, 1998). Its presence or absence is considered either an enabler or a barrier to knowledge sharing (Kogut \& Zander, 1992; Hansen, 2002). However, literature has not considered the effects that poorly codified knowledge and knowledge complexity have on KR. Indeed, researchers have adopted an unproblematic approach to the process of codification (Hall, 2006) and have often presumed that the quality of codified knowledge should be high. They therefore suggest that companies have to enhance KR activities in order to increase performance (Kogut \& Zander, 1992; Haas \& Hansen, 2007). Instead, we suggest that, in conditions of high knowledge complexity, companies should balance codification and personalization strategies (Hansen et al., 1999) and they have to closely monitor the quality of the codified knowledge.

Our findings fail to provide evidence of the argument that knowledge management systems enhance KR (Markus, 2001; Kankanhalli et al., 2005). Previous studies have investigated successful reuse scenarios and the motivating factors that enhance KR (Markus, 2001). Other scholars have found that the valence of knowledge (perceived value of knowledge accessed) influenced KR frequency (Watson \& Hewett, 2006). The findings of this study show that the poor quality of the codified knowledge is a critical barrier to KR from an electronic repository within the product prototyping stage. Furthermore, the results show that poor knowledge quality can be determined by several reasons; the most important reasons are as follows: the lack of accuracy of the codified knowledge, followed by knowledge incompleteness and by the lack of adoption of a consistent/shared format of knowledge representation throughout the organization. This finding advances the understanding of knowledge quality dimensions that are willing to affect KR within NPD environments.

This study has also explored the implications of KS and KR for the performance of the VPPD stage within the NPD process, thereby advancing the literature on the links between knowledge management, electronic repositories and NPD performance. The results of this study suggest that the time and costs saved by reusing and leveraging existing knowledge could be among the benefits of a knowledge repository providing that it fosters effective KR and KS. We agree with Zhou et al. (2014) that the level of their information quality stored within information technology can contribute to achieve good overall business performance and with $\mathrm{Yu}$ et al. (2014) that knowledge acquisition facilitates NPD performance positively. However, the present study's findings show that having high quality knowledge is not enough to improve business performance; R\&D staff should be in the condition of efficiently sourcing codified knowledge to be able to reuse such knowledge. Potential inefficiencies in the sourcing of knowledge may otherwise produce scale diseconomies in $\mathrm{KR}$ and exploi tation. Although vast amounts of knowledge can be created, codified and archived into a repository, the difficulties in the retrieval and reuse of knowledge can create dissatisfaction and unwillingness to reuse the repository in the future (reuse intentions). It is well known that the reuse of existing design knowledge is the key to realize rapid product design (Lu et al., 2011). In the case investigated in this study, R\&D employees prefer to source knowledge from other colleagues and to recreate a solution to a problem from scratch. This dynamic produces duplication of efforts (and of knowledge) and increases the time needed in the product design stage, and such inefficiencies can negatively affect first-mover advantages (Eisenhardt \& Tabrizi, 1995).

It is argued that the capacity of rapidly design new products that meet market needs is crucial in highly competitive markets (Thomke, 2003), and the design (including assembly and prototyping) of a new vehicle is a costly process in any manufacturing company. Research in fact shows that approximately $80 \%$ of the manufacturing cost of a product is determined by the design of a product (Clark \& Fujimoto, 1991). In this study, we have acknowledged that if from one side digital assembly technology can shorten delivery time and reduce assembly cost (Xu et al., 2012; Xu et al., 2014), which finding advances industrial informatics literature of how digital assembly is implemented (Butterfield et al., 2007), on the other side, the inefficiencies in the sourcing and reusing of knowledge may have negative repercussions on the time performance within the product prototyping stage.

It is useful to point out that the inefficiencies in $\mathrm{KR}$ and KS may have an impact on the VPPD at different points in time. For example, daily, by increasing the time needed to solve technical problems, and diachronically, when experienced or key employees leave the company and their knowledge and expertise leave with them (March, 1991). In fact, the problems of incorrect codification of knowledge also offset the potential benefits of repositories, which are generally created to retain the knowledge held by employees who leave a company (Dalkir, 2005). Accordingly, if an organization does not establish clear and shared (throughout the organization and the partners) guidelines and norms about the way knowledge should be codified and archived into an organizational repository, the risk that the repository will not be used effectively and will not fulfil the purpose for which it has been implemented is high.

Finally, this study has shed light on how knowledge repositories are being used as a support to virtual simulation technologies in the product prototype development process and specifically a virtual vehicle prototype. We have shed 
light on the knowledge-related activities in the NPD process and more specifically in the virtual product prototyping advancing the management and information systems literatures (Vaccaro et al., 2011; Yu et al., 2014).

\section{Managerial implications}

The current research has explored the barriers to knowledge sourcing and reuse from an electronic repository and their implications for the product prototyping stage of NPD. The study offers some practical suggestions on how information system specialists and R\&D managers could overcome KS and KR barriers.

This study has found that the lack of interoperability between different systems and repositories, the ineffective search functionalities and the ambiguous (or duplicated) directories/folders/repositories are important factors that negatively affect the ease of use of a repository. A system developer in charge with the design of a repository that is used as a support to product development teams should take into account the barriers to KS identified in this study before implementing the repository. We have seen that the DMU software detects problems (e.g. interference) in the vehicle assembly; however, it does not provide a solution to the detected problem, so $R \& D$ people have to retrieve a solution from the repository to solve the problem. Technological advances in product assembly software could reduce KS problems; for instance, new software for design assembly of complex products (e.g. AutoAssem) is able to find and compare solutions automatically minimizing manual input (Xu et al., 2012).

According to the findings, the adoption of domain ontologies could be a viable solution for improving the effectiveness of search functionalities so as to enhance KS. An ontology is a meta-level description of knowledge presentation; it provides search engines with the functionality of a semantic match (Guarino, 1997). A domain ontology creates a shared language about a domain or topic (i.e. vehicle components) in order to facilitate knowledge communication, storing, searching and sharing in knowledge management systems (O'leary, 1998). In ontology-based searches, the data input is converted into semantic statements, by capturing and classifying the knowledge contained using domain ontology (Dadzie et al., 2009). Ontologies may enable employees to immediately locate the knowledge related to a problem area and to a specific irregularity stored in a repository, and also the relationship with other similar problems and solutions. Thus, developments in the area of knowledge representation and ontology mapping will lead to improvements in the ability to create, share and exchange knowledge for solving design evaluation problems involving multiple applications and viewpoints (Zhan et al., 2010; Chandrasegaran et al., 2013).

Furthermore, researchers in industrial informatics and enterprise systems view business intelligence (BI) technologies (e.g. data warehouses, data mart, data mining and online analytical processing) as capable of efficiently extracting and delivering useful information from large data for decisionmaking (Duan \& Xu, 2012). Thus, in the process of building of a virtual prototype of a vehicle, the development of domain ontology or the adoption of BI could help engineers to rapidly and efficiently locate the knowledge needed (e.g. solution) to solve problems (e.g. irregularity) in the vehicle development process.

Another solution that could be adopted to improve KS from a repository is the creation of folksonomies or social tagging of documents. Folksonomies allow for the multiple, overlapping associations that the brain itself uses rather than the rigid categories of taxonomies and folders (O'reilly, 2005). Social tagging is a bottom-up, collaborative categorization of contents and resources using freely chosen keywords, often referred to as tags. The pieces of knowledge archived into repositories can be tagged by R\&D workers, and in such a way, they contribute to the creation of a shared and more flexible categorization of knowledge. Organizations could also consider adopting named entity recognition systems to enhance the extraction of knowledge and text mining (Pan et al., 2014) or meta-models that are useful for information integration, sharing, searching, reading and operation (Xu et al., 2014).

An implication of this study's findings for information system specialists is that repositories should be integrated with expert networks, especially when the codified knowledge is highly complex or unstructured as within the prototyping stage of vehicle products. Expert networks are networks of individuals, identified as experts in some professional areas, who are electronically accessible by others with questions related to that expertise (King et al., 2002). The difficulty in understanding and interpreting the knowledge stored in a repository could be minimized if the knowledge seeker could communicate with the contributor of such knowledge in a timely manner.

Another solution to the problems in KS and KR found in this study could be the implementation of 'communities of practices' (Wenger \& Snyder, 2000). Communities of practice are gaining some recognition in the automotive industry as effective organizational mechanisms for the creation, codification and sharing of both implicit and explicit knowledge (Wolf et al., 2011). Thus, R\&D managers could implement inter-departmental communities of practice to develop a shared terminology, taxonomy and format to be adopted for the codification of knowledge. They could also refine and improve the quality of the codified knowledge that has been created and archived within a repository. Moreover, they could work to provide a better organization of the way knowledge is archived within the company's systems.

\section{Limitations and future research}

The present research has some limitations. First, the focus on a large private supplier of $R \& D$ in the automotive industry could limit the findings to the context investigated 
by the researcher. Scholars could undertake a comparative study with another company in the same or in a different industry with the purpose of getting a cross-company/ cross-industry validation of the results obtained here. Although the findings of this research come from a single company, we believe that many other R\&D centres in the automotive industry can learn from this study. In fact, many automotive $R \& D$ centres are currently introducing virtual simulation technologies and electronic knowledge repositories (Dodgson et al., 2007), and therefore, they may be facing the same challenges of the R\&D supplier considered in this study. Moreover, the lack of research on the topic and the importance of the implications of the factors identified in this study increase the value of our findings.

Second, this study has adopted a qualitative method of investigation based on interviews with $\mathrm{R} \& \mathrm{D}$ people, which limits the possibility to quantify the strength of the relationships between the variables considered in this study. Therefore, a quantitative validation of the theoretical framework developed through this study is needed. Structural equation modelling could be used to test the potential relationships among all the variables in the framework (Figure 1).

Third, another limitation of this research could be that it has not tested the influence of environmental conditions and the characteristics of individuals. These have been found to be important factors when trying to understand the impact of information systems-enabled learning mechanisms on knowledge exploration and exploitation (Kane \& Alavi, 2007; Durcikova et al., 2011).

\section{Conclusions}

Focusing on the product prototyping process in the automotive industry, this study has found the following: (1) KS from a repository is inhibited by the difficulty of use of a repository, which is determined by ineffective search functionalities, ambiguous repository and folder names, and lack of interoperability between different systems/repositories; (2) $\mathrm{KR}$ from a repository is inhibited by inefficiencies in KS and by the poor quality of the codified knowledge; (3) the degree of complexity of knowledge acts as moderator in the relationship between system quality and knowledge quality and respectively KS and KR; and (4) KS and KR influence the time performance of the virtual product prototyping process.

\section{Acknowledgements}

We wish to thank the staff at the R\&D centre for giving us the possibility to collect the data for this study and Prof. Pierpaolo Andriani, Prof. Giuseppina Passiante, Prof. Angelo Corallo, Prof. Franco Carassiti, Prof. Aldo Romano for their help, recommendations and support.

\section{References}

Alavi, M. and D. Leidner (2001) Knowledge management and knowledge management systems: conceptual foundations and research issues, MIS Quarterly 25, 117-136.

Abernathy, W.J. (1978) The Productivity Dilemma. Johns Hopkins University Press, Baltimore.

Argote, L., B. Mcevily and R. Reagans (2003) Managing knowledge in organizations: an integrative framework and review of emerging themes, Management Science 49, $571-582$.

BRown, J.S. and P. Duguid (2001) Knowledge and organization: a social-practice perspective, Organization Science 12, 198-213.

Butterfield, J., S. Crosby, R. Curran, M. Price, C.G. Armstrong, S. Raghunathan and C. Gibson (2007) Optimization of aircraft fuselage assembly process using digital manufacturing, Journal of Computing and Information Science in Engineering 7, 269-275.

Carlile, P. and E. Rebentisch (2003) Into the black box: the knowledge transformation cycle, Management Science 49, $1180-1195$.

Chandrasegaran, S.K., K. Ramani, R.D. Sriram, I. Horváth, A. Bernard, R.F. HARIK and W. GAO (2013) The evolution, challenges, and future of knowledge representation in product design systems, Computer-Aided Design 45, 204-228.

Cheung, P.-K., P.Y.K. Chau and A.K.K. Au (2008) Does knowledge reuse make a creative person more creative? Decision Support Systems 45, 219-227.

Clark, K.B. and T. Fujimoto (1991) The power of product integrity, Harvard Business Review 68, 107-18.

Constant, D., L. Sproull and S. Kiesler (1996) The kindness of strangers: the usefulness of electronic weak ties for technical advice, Organization Science 7, 119-135.

CoOper, R.G. (1990) Stage-gate systems: a new tool for managing new products, Business Horizons May-June 33(3), 44-54.

Cooper, R.G. (2008) Perspective: the Stage-Gates idea-to-launch process - update, what's new, and NexGen systems, Journal of Product Innovation Management 25, 213-232.

Corallo, A., R. Laubacher, A. Margherita and G. Turrisi (2009) Enhancing product development through knowledgebased engineering (KBE): a case study in the aerospace industry, Journal of Manufacturing Technology Management 20, $1070-1083$.

Cummings, J.N. (2004) Work groups, structural diversity, and knowledge sharing in a global organization, Management Science 50, 352-364.

Dadzie, A.S., R. Bhagdev, A. Chakravarthy, S. Chapman, J. Iria, V. Lanfranchi and F. Ciravegna (2009) Applying semantic web technologies to knowledge sharing in aerospace engineering, Journal of Intelligent Manufacturing 20, 611-623.

DALKIR, K. (2005) Knowledge management in theory and practice. Burlington: Elsevier, Butterworth-Heinemann.

DavenPort, T.H. and L. PrusaK (1998) Working Knowledge: How Organizations Manage What They Know. Massachusetts, Boston: Harvard Business School Press.

DAvis, F.D. (1989) Perceived usefulness, perceived ease of use and user acceptance of information technology, MIS Quarterly 13 , $319-340$.

Dixon, N. (2002) The neglected receiver of knowledge sharing, Ivey Business Journal March/April, 35-40.

Dodgson, M., D.M. GANn and A. SAlter (2007) In the case of fire, please use the elevator: simulation technology and organization in fire engineering, Organization Science 18, 849-64.

Durcikova, A., K.J. Fadel, B.S. Butler and D.F. Galletta (2011) Knowledge exploration and exploitation: the impacts of psychological climate and knowledge management system access, Information Systems Research 22, 855-866. 
Durcikova, A. and P. Gray (2009) How knowledge validation processes affect knowledge contribution, Journal of Management Information Systems 25, 81-107.

Dyer, J. and I. Nobeoka (2000) Creating and managing a highperformance knowledge transfer network: the Toyota case, Strategic Management Journal 21, 345-367.

Eisenhardt, K.M. and F.M. Santos (2002) Knowledge-based view: a new theory of strategy? In Pettigrew, A., H. Thomas and R. Whittington (eds.) Handbook of Strategy and Management. London, UK: Sage, 139-164.

EISENHARDT, K.M. and B.N. TABRIZI (1995) Accelerating adaptive processes: product innovation in the global computer industry, Administrative Science Quarterly 40, 84-110.

EtTLie, J.E. and M. KubAREK (2008) Design reuse in manufacturing and services, Journal of Product Innovation Management 25, 457-472.

Flanagan, J.C. (1954) The critical incident technique, Psychological Bulletin 51, 327-358.

Goodman, P.S. and E.D. DARR (1998) Computer-aided systems and communities: mechanisms for organizational learning in distributed environments, MIS Quarterly 22, 417-440.

Glaser, B.G. and A.L. Strauss (1967) The Discovery of Grounded Theory: Strategies for Qualitative Research. Chicago: Aldine Publishing Company.

GRANT, R.M. (1996) Prospering in dynamically-competitive environment: organizational capability as knowledge integration, Organization Science 7, 375-88.

Gray, P. and A. Durcikova (2006) The role of knowledge repositories in technical support environments: speed versus learning in user performance, Journal of Management Information Systems 22, 159-190.

Gray, P.H. and D.B. Meister (2006) Knowledge sourcing methods, Information \& Management 43, 142-156.

GuARINO, N. (1997) Understanding, building and using ontologies, International Journal of Human-Computer Studies 46, 293-310.

Hall, M. (2006) Knowledge management and the limits of knowledge codification, Journal of Knowledge Management 10, $117-126$

Hansen, M.T., N. Nohria and N. Tierney (1999) What's your strategy for managing knowledge, Harvard Business Review 77, $106-116$

HANSEN, M.T. (1999) The search-transfer problem: the role of weak ties in sharing knowledge across organization subunits, Administrative Science Quarterly 44, 82-111.

HANSEN, M.T. (2002) Knowledge networks: explaining effective knowledge transfer in multiunit companies, Organization Science 13, 232-248.

HaAs, M.R. and M.T. HANSEN (2007) Different knowledge, different benefits: toward a productivity perspective on knowledge sharing in organizations, Strategic Management Journal 28, 1133-1153.

Kane, G.G. and M. Alavi (2007) Information technology and organizational learning: an investigation of exploration and exploitation processes, Organization Science 18, 796-812.

Kankanhalli, A., B.C.Y. TAN and W. KwOK-KeE (2005) Understanding seeking from electronic knowledge repositories: an empirical study, Journal of the American Society for Information Science and Technology 56, 1156-1166.

King, W., V.P. Marks and S. Mccoy (2002) The most important issues in knowledge management, Communications of the ACM 45, 93-97.

Kogut, B. and U. Zander (1992) Knowledge of the firm, combinative capabilities, and the replication of technology, Organization Science 3, 383-397.

Kotabe, M., X. Martin and H. Domoto (2003) Gaining from vertical partnerships: knowledge transfer, relationship duration, and supplier performance improvement in the U.S. and Japanese automotive industries, Strategic Management Journal 24, 293-316.
Kvale, S. (2007) Doing Interviews. London: Sage Publications.

Jansen, J.J.P., F.A.J. VAn Den Bosch and H.W. Volberda (2006) Exploratory innovation, exploitative innovation, and performance: effects of organizational antecedents and environmental moderators, Management Science 52, 1661-1674.

JARVENPAA, S.L. and D.S. STAPLES (2000) The use of collaborative electronic media for information sharing: an exploratory study of determinants, The Journal of Strategic Information Systems $\mathbf{9}$, $129-154$.

Jordan, J. and P. JONES (1997) Assessing your company's knowledge management style, Long Range Planning 30, 392-98.

Lakshman, C. and R.C. Parente (2008) Supplier-focused knowledge management in the automobile industry and its implications for product performance, Journal of Management Studies 45, 317-342.

Larsson, R., L. Bengtsson, K. Henriksson and J. Sparks (1998) The interorganizational learning dilemma: collective knowledge development in organizational alliances, Organization Science $\mathbf{9}$, 285-305.

LeE, B. and K. SAItou (2004) Integrated synthesis of assembly and fixture scheme for properly constrained assembly, in ASME 2004 International Design Engineering Technical Conferences and Computers and Information in Engineering Conference. American Society of Mechanical Engineers, 863-875.

Levitt, B. and J.G. MARCh (1988) Organizational learning, Annual Review of Sociology 14, 319-340.

Lu, C.M., S. Zheng, W. Jin, Y.F. Sheng and Y. Sun (2011) Template-based expression and reuse of design knowledge, Advanced Materials Research (328-330), 274-278.

DuAN, L. and L.D. Xu (2012) Business intelligence for enterprise systems: a survey, IEEE Transactions on Industrial Informatics, 8, 679-687.

Lilleoere, A.M. and E.H. HAnsen (2011) Knowledge-sharing enablers and barriers in pharmaceutical research and development, Journal of Knowledge Management 15, 53-70.

MajchrzaK, A., L.P. Cooper and O.E. Neece (2004) Knowledge reuse for innovation, Management Science 50, 174-188.

Malmotra, Y. (2004) Why knowledge management systems fail: enablers and constraints of knowledge management in human enterprise. In Koenig, E. and T.K. Srikantaiah (eds.) Knowledge Management: Lessons Learned: What Works and What Doesn't, American Society for Information Science and Technology Monograph Series,Information Today, Medford, NJ, 87-112.

MARCH, J.G. (1991) Exploration and exploitation in organizational learning, Organization Science 2, 71-87.

MARKUS, L. (2001) Towards a theory of knowledge reuse: types of knowledge reuse situations and factors in reuse success, Journal of Management Information Systems 18, 57-93.

Nelson, R.R., P.A. TodD and B.H. Wixom (2005) Antecedents of information and system quality: an empirical examination within the context of data warehousing, Journal of Management Information Systems 21, 199-235.

NonAKA, I. (1991) The knowledge creating company, Harvard Business Review 69, 96-104.

O'Dell, C. and C.J. Grayson (1998) If only we knew what we know: identification and transfer of internal best practices, California Management Review 40, 154-174.

OfeK, E. and M. SARVARY (2001) Leveraging the customer base: creating competitive advantage through knowledge management, Management Science 47, 1441-1456.

O'LEARY, D.E. (1998) Enterprise knowledge management, Computer 31, 54-61.

O'ReILly, T. (2005) What is Web 2.0: design patterns and business models for the next generation of software, September 30th, available at: http://www.oreillynet.com/pub/a/oreilly/tim/news/ 2005/09/30/what-is-web-20.html (accessed 27 November 2012). 
Pan, S., L. Wang, K. Wang, Z. Bi, S. Shan and B. Xu (2014) A knowledge engineering framework for identifying key impact factors from safety-related accident cases, Systems Research and Behavioral Science 31, 383-397.

Prahalad, C.K. and G. Hamel (1990) The core competence of the corporation, Harvard Business Review 68, 79-91.

RAO, L. and K.-M. OSEI-BRYSON (2007) Towards defining dimensions of knowledge systems quality, Expert Systems with Applications 33, 368-378.

RugGles, R.L. (1997) Knowledge Management Tools. London: Butterworth-Heinemann.

Silverman, D. (2010) Qualitative Research. London: Sage Publications.

Strauss, A. and J. Corbin (1998) Basics of Qualitative Research: Techniques and Procedures for Developing Grounded Theory. Thousand Oaks, CA: Sage.

Sun, G., W. REN and J. ZHANG (2011) Virtual product development for an automotive universal joint, International Journal of Automotive Technology 12, 299-305.

TeECE, D. (1986) Profiting from technological innovation: implications for integration, collaboration, licensing and public policy. Research Policy 15, 285-305.

Thомке, S.H. (2003) Experimentation Matters: Unlocking the Potential of New Technologies for Innovation, Boston, MA: Harvard Business School Press.

Vaccaro, A., S. Brusoni and F.M. Veloso (2011) Virtual design, problem framing, and innovation: an empirical study in the automotive industry, Journal of Management Studies 48, 99-122.

Wang, L., S. Keshavarzmanesh, H.Y. Feng and R.O. Buchal (2009) Assembly process planning and its future in collaborative manufacturing: a review, The International Journal of Advanced Manufacturing Technology 41, 132-144.

WASKO, M.M. and S. FARAJ (2005) Why should I share? Examining social capital and knowledge contribution in electronic networks of practice, MIS Quarterly 29, 35-57.

Watson, S. and K. Hewett (2006) A multi-theoretical model of knowledge transfer in organizations: determinants of knowledge contribution and knowledge reuse, Journal of Management Studies 43, 141-173.

Wenger, E. and W.M. SNYder (2000) Communities of practice: an organizational frontier, Harvard Business Review 78(1), 139-145.

WiNTER, S.G. (1987) Knowledge and competence as strategic assets. In Teece D.J. (ed.), The Competitive Challenge: Strategies for Industrial Innovation and Renewal, Ballinger: Cambridge, MA, 159-184.

Wolf, P., S. Spath and S. Haefliger (2011) Participation in intrafirm communities of practice: a case study from the automotive industry, Journal of Knowledge Management 15, 22-39.

WU, J.-H. and Y.-M. WANG (2006) Measuring KMS success: a respecification of the DeLone and McLean's model, Information \& Management 43, 728-739.

XU, L.D., C. Wang, Z. BI and J. Yu (2012) AutoAssem: an automated assembly planning system for complex products, IEEE Transactions on Industrial Informatics, 8, 669-678.

XU, L.D., C. WANG, Z. BI and J. YU (2014) Object-oriented templates for automated assembly planning of complex products, IEEE Transactions on Automation Science and Engineering 11, 492-503.
YIN, R. (2003) Case Study Research. Design and Methods, $3^{\text {rd }}$ Edn, Thousand Oaks, CA: Sage Publications.

Yli-Renko, H., E. Autio and H.J. SAPIENZA (2001) Social capital, knowledge acquisition, and knowledge exploitation in young technology-based firms, Strategic Management Journal 22, 587-613.

Yu, X., Y.I. Chen and B. NGUYen (2014) Knowledge management, learning behavior from failure and new product development in new technology ventures, Systems Research and Behavioral Science 31, 405-423.

Zhan, P., U. JAYARAm, O. Kim and L. Zhu (2010) Knowledge representation and ontology mapping methods for product data in engineering applications, Journal of Computing and Information Science in Engineering 10, 021004.

Zhou, H., Y. Shou, X. Zhai, L. Li, C. Wood and X. Wu (2014) Supply chain practice and information quality: a supply chain strategy study, International Journal of Production Economics 147, 624-633.

\section{The authors}

\section{Dr Raffaele Filieri}

Dr Raffaele Filieri is a Senior Lecturer in Marketing at Newcastle Business School, Northumbria University, UK. $\mathrm{He}$ received his $\mathrm{PhD}$ in Business Engineering from Universita' Roma Tre (Department of Mechanical Engineering) and his post-doc from La Sapienza Universita' di Roma. His main research interests revolve around knowledge management, knowledge transfer process, innovation management, knowledge management systems implementation and electronic marketing. His papers have been accepted for publication in Industrial Marketing Management; Journal of Knowledge Management; Inter national Journal of Quality and Reliability Management; International Journal of Agile Systems and Management; Journal of Business Strategy; Marketing Intelligence \& Planning; Journal of Travel Research; and Journal of Direct, Data and Digital Marketing Practice.

\section{Dr Salma Alguezaui}

Salma Alguezaui is a $\mathrm{PhD}$ student in Business Engineering at Universita' del Salento, Italy. Salma's actual publications include academic articles in peer-reviewed journals such as Journal of Knowledge Management, International Journal of Agile Systems and Management, and Journal of Business Strategy. Salma's main research interests include international business management, strategy, knowledge and innovation management, and business process reengineering. 